\title{
Papular-Purpuric "Gloves and Socks" Syndrome Caused by Parvovirus B19 Infection in Brazil: A Case Report
}

\author{
Marcos Tadashi Kakitani Toyoshima ${ }^{1}$, \\ Lilian Walsh Keller' ${ }^{2}$, Maria Luisa Barbosa ${ }^{2,3}$ \\ and Edison Luiz Durigon ${ }^{2}$
}

\author{
${ }^{1}$ Department of Internal Medicine of University of São Paulo \\ School of Medicine, ${ }^{2}$ Institute of Biomedical Sciences, University \\ of São Paulo, ${ }^{3}$ Adolfo Lutz Institute; São Paulo, SP, Brazil
}

\begin{abstract}
Papular-purpuric "gloves and socks" syndrome (PPGSS) is a novel, rare, self-limiting dermatosis caused by human parvovirus B19. It consists of pruritic edema and erythema of the hands and feet in a gloves-and-socks distribution, and it is associated with oral lesions and fever. We present a case of PPGSS in a 22-year-old Brazilian woman. Clinical and laboratory evaluation, including serological tests, PCR and gene sequencing, confirmed the presence of human parvovirus B19.

Key Words: Dermatosis, gloves and socks, parvovirus B19, PCR, sequencing
\end{abstract}

Parvovirus B19 (B19) was discovered by Yvonne Cossart, an Australian virologist working in London in 1975; it was first linked to a disease by John Pattison in 1981 [1]. Parvovirus B19 is until recently the only member of the large Parvoviridae family that has been directly associated with human infection $[1,2]$. Infection with B19 is distributed worldwide and has been associated with a broad spectrum of clinical syndromes that vary with the age and clinical conditions of the host [1,3]. Papular-purpuric "gloves and socks" syndrome (PPGSS) is a novel, rare, self-limiting dermatosis caused by B19.

We described a case of PPGSS that occurred in a healthcare professional with acute parvovirus B19 infection.

\section{Case Report}

A 22-year-old woman, a nurse technician, was admitted to the emergency department of "Hospital Universitário" of the University of São Paulo with a 3-day history of ecchymosis on the left hand index finger and daily fever $\left(39.0^{\circ} \mathrm{C}\right)$ that did not decrease with dipirone. Several purpuric papules rapidly developed on the palms, back of her hands and feet. These lesions were not pruriginous. The patient was previously healthy with no preceding upper respiratory tract infection, no abdominal pain or diarrhea, and no joint pain or swelling. There was no history of blood transfusion, or foreign travel. On admission, the physical examination showed multiple purpuric skin lesions on the dorsa and palms of both hands and on the feet. These skin lesions were petechial and marginated on the wrists and the ankles. The patient was febrile $\left(40.0^{\circ} \mathrm{C}\right)$ and in good general condition. No peripheral lymph nodes, liver or spleen enlargements were present.

Received on 22 Novermber 2005; revised 21 January 2006. Address for correspondence: Dr. Marcos Tadashi Kakitani Toyoshima - Rua Professor Antonio Prudente, 41 apto. 506 Liberdade - São Paulo-SP-Brazil. Zip code: 01509-010. Telephone: 55-11-3207-3840.E-mail: mtkt@terra.com.br

The Brazilian Journal of Infectious Diseases 2006;10(1):62-64. (C) 2006 by The Brazilian Journal of Infectious Diseases and Contexto Publishing. All rights reserved.
Multiple erythematous macules and papules could be seen on the hard palate. No signs of meningeal irritation were seen. The initial vital signs were a pulse of $124 / \mathrm{min}, 39.7^{\circ} \mathrm{C}, 120 /$ $80 \mathrm{mmHg}$ blood pressure and a respiratory rate of $20 / \mathrm{min}$.

Initial laboratory tests revealed mild leukopenia $(4,500 /$ $\mathrm{mL}$, with a differential count of $3 \%$ unsegmented neutrophils, $73 \%$ segmented neutrophils, $16 \%$ lymphocytes, 720 lymphocytes, $6 \%$ eosinophils and $2 \%$ monocytes) and thrombocytopenia $\left(106 \times 10^{3}\right.$ platelets $\left./ \mathrm{mL}\right)$. Renal and hepatic functions, serum electrolytes (sodium, potassium, and calcium) and coagulation tests were within normal ranges. No alteration was observed in abdominal ultrasonography. The patient was admitted for further diagnostic investigation.

One day after she had been interned, petechiae affected wrists, ankles and the distal third region of the legs. At the same time, oral enanthema with small painful vesicles appeared. Laboratory exams showed an erythrocyte sedimentation rate of $58 \mathrm{~mm}$ per hour and $28 \mathrm{mg}$ C-reactive protein/dL. We alternated dipirone and acetaminophen to reduce the fever. Four pairs of blood cultures (aerobic and anaerobic Bactec ${ }^{\circledR}$ ) were collected after admission, and all the results were negative.

On the third day of admission, petechiae could be seen up to the thighs, especially on the right thigh. The vesicles with hematic crusts in the oral cavity and on the lips were so painful that it was difficult for the patient to open her mouth and eat. The leukocyte and platelet counts reached their lowest level: $2.8 \times 10^{3} / \mathrm{mL}$ (280 lymphocytes) and $83 \times 10^{3} / \mathrm{mL}$, respectively. After seven days of illness, the exanthema started to recede and they were limited to the wrists. It was the first day without fever. There was not complete remission of purpura; a few crusts on the lips were still painful.

Serological tests were performed during hospitalization. Serology for viral hepatitis A, B and C, syphilis, Epstein-Barr virus, rubella, enterovirus, toxoplasmosis, Chagas disease, HIV and cytomegalovirus, excluded recent infections. A serum sample was collected for dengue serology on the seventh day of illness, with a negative result. We then considered the possibility of papular-purpuric "gloves and socks" syndrome, whose principal etiological agent is human parvovirus B19. 
The ELISA test for B19 virus was positive for IgM and IgG antibody using a commercial assay (Biotrim Inc.). The presence of B19 DNA were first screened by a nested polymerase-chain-reaction assay for amplification of the NS1 encoding region, with external primers designed $\mathrm{P} 1$ and $\mathrm{P} 6$ and internal primers P2 and P5 [4]. Phylogenic analysis of the VP2 gene indicated that the Br572 B19 strain from this Brazilian patient had a high degree of homology with other published B19 sequences [5] (Figure 1).

Eleven days after admission, the patient was discharged in good condition, without fever for five days, along with complete regression of the rash and the enanthema.

A new laboratory exam was made after two months; the results returned to normal. The platelet and leukocyte counts were $201 \times 10^{3} / \mathrm{mL}$ and $5.6 \times 10^{3} / \mathrm{mL}$ (1960 lymphocytes), respectively. The C-reactive protein was less than $5 \mathrm{mg} / \mathrm{dL}$ and the coagulogram was normal. Serological tests showed negativity for anti-B19 IgM and no B19 DNA was detected by PCR analysis.

\section{Discussion}

Most cases of parvovirus B19 infection are asymptomatic. The most common clinical presentations include dermatological involvement, such as erythema infectiosum (or fifth disease), hematological findings such as transient aplastic crisis or chronic anemia in the immunocompromised host, rheumatological manifestations, such as arthritis without joint destruction, and if infection occurs during pregnancy, B19 may lead to miscarriage or hydrops fetalis [2].

Although parvovirus B19 is usually transmitted by the respiratory route, administration of contaminated blood and plasma-derived products, particularly clotting factors, can also result in transmission [2]. It is mildly contagious and infection may occur sporadically or in epidemics. Hospital workers have not been found to be at high risk of infection during endemic periods. However, hospital acquisition and transmission have been reported after exposure to patients with acute infection. Serological or DNA evidence of B19 has been reported in some patients with necrotizing vasculitis, Kawasaki's disease, Henoch-Schönlein purpura, giant-cell arteritis, hepatitis and myocarditis [1]. The papular-purpuric "gloves and socks" syndrome is a rare manifestation of B19 infection.

Harms et al. first described the clinical features of PPGSS in 1990 [6], but the etiological association with HPV B19 became known in 1991, when IgM anti-B19 was detected in a patient's serum [7]. Most cases of PPGSS occur in young adults, and it equally affects men and women, during spring and summer seasons [8,9]. Likely other manifestations, the reasons for this predominance are unknown.

The clinical manifestations of PPGSS consist of progressive painful and pruritic symmetric swelling and erythema of the hands and feet in a gloves-and-socks distribution, and association with oral lesions and fever.
Figure 1. Dendrogram showing the genetic relation of the BR 572 isolate of parvovirus B19 based on the VP2 coding region, compared with other parvoviruses

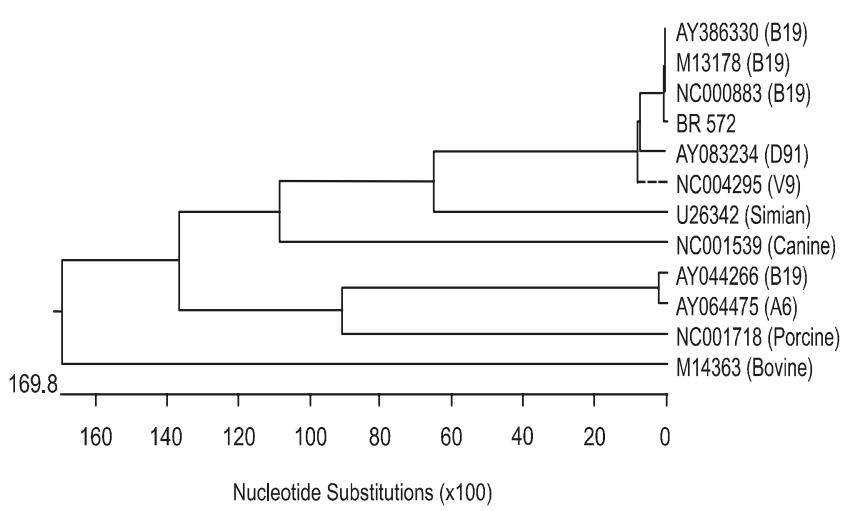

Lesions extend to the wrists and ankles. Exanthema may be less frequently involved, including on the cheeks, elbows, knees, the inner side of thighs, and buttocks. Mucosal involvements can include petechiae on the hard palate, vesiculopustules on the hard and soft palates, pharyngeal erythema, small erosions on the oral mucosa, and swollen lips. Lymphadenopathy is a common feature, but it was not present in our patient. Laboratory findings include leukopenia, anemia, thrombocytopenia and elevated liver enzyme levels. The erythrocyte sedimentation rate and C-reactive protein level are infrequently increased $[8,10,11]$. We observed a prominent lymphopenia in our patient.

Parvovirus B19 is the principal etiological agent of PPGSS. Other viral agents, such as cytomegalovirus, measles virus, coxsackie B6, Epstein-Barr, rubella, human herpes virus types 6 and 7, and hepatitis B have been associated with this syndrome [11, 12, 13]. Parvovirus B19 can be demonstrated as the etiological agent by seroconversion after performing viral serological tests, or B19-DNA can be identified by PCR in the serum or in cutaneous biopsy specimens [11].

In several B19-related PPGSS cases, B19-specific IgM antibody was not detected in the serum at the time of the initial clinical features [13]. In our case, the serological test was positive for B19-specific IgG and IgM; the nested-PCR detected B19 DNA, as also found in other cases $[11,12,14]$. The nucleotide sequence of our isolate, when compared with other genotypes, confirmed the presence of B19; the genomic variability in the region encoding VP2 differ by conspicuously little in their sequences [5].

Parvovirus B19 infection can be associated with a wide spectrum of human illnesses that range from an asymptomatic condition to life-threatening disease, but the full spectrum of this virus-induced disease is not totally defined. To summarize, PPGSS is a rare cause of dermatosis, and parvovirus B19 is 
the principal etiological agent. This infection is usually brief and self-limiting, and it can affect previously healthy patients.

\section{References}

1. Young N.S., Brown K.E. Parvovirus B19. N Engl J Med 2004;350:586-97.

2. Wiss K., Brown T.J. Parvovirus B19. In: Tyring S.K. Mucocutaneous manifestations of viral diseases. New York: Marcel Dekker, Inc., 2002.

3. Anderson M.J. Parvoviruses as Agents of Human Disease. Prog. Med Virol 1987;34:55-69.

4. Durigon E.L., Erdman D.D., Gary G.W., et al. Multiple primer pairs for polymerase chain reaction (PCR) amplification of human parvovirus B19 DNA. J Virol Methods 1993; 44:155-65.

5. Erdman D.D., Durigon E.L., Wang Q.Y., Anderson L.J. Genetic diversity of human parvovirus B19: sequence analysis of the VP1/VP2 gene from multiple isolates. J Gen Virol 1996; 77:2767-74.

6. Harms M., Feldmann R., Saurat J.H. Papular-purpuric "gloves and socks" syndrome. J Am Acad Dermatol 1990;23:850-4.

7. Bagot M., Revuz J. Papular-purpuric "gloves and socks" syndrome: primary infection with parvovirus B19? J Am Acad Dermatol 1991;25:341-2.
8. Borradori L., Cassinotti P., Perrenoud D., et al. Papularpurpuric "gloves and socks" syndrome. Int J Dermatol 1994; 33:196-7.

9. Veraldi S., Rizzitelli G., Scarabelli G., et al. Papular-purpuric "glove and socks" syndrome. Arch Dermatol 1996;132:975.

10. Alfradley A, Aljubran A, Hainau B, Alhokail A. Papular-purpuric "gloves and socks" syndrome in a mother and daughter. J Am Acad Dermatol. 2003;48:941-4.

11. Sklavounou-Andrikopoulou A., Lakovou M., Paikos S., et al. Oral manifestations of papular-purpuric 'gloves and socks' syndrome due to parvovirus B19 infection: the first case presented in Greece and review of the literature. Oral Dis 2004; 10:118-22.

12. Passoni L.F., Ribeiro S.R., Giordani M.L., et al. Papularpurpuric "gloves and socks" syndrome due to parvovirus B19: report of a case with unusual features. Rev Inst Med Trop Sao Paulo 2001;43:167-70.

13. Smith P.T., Landry M.L., Carey H., et al. Papular-purpuric gloves and socks syndrome associated with acute parvovirus B19 infection: case report and review. Clin infect Dis 1998; $27: 164-8$.

14. Aractingi S., Bakhos D., Flageul B., et al. Immunohistochemical and virological study of skin in the papular-purpuric gloves and socks syndrome. Br J Dermatol 1996;135:599-602. 